\title{
Luta que não acaba: os direitos das mulheres
}

\section{Angela de Castro Gomes*}

FRACCARO, Glaucia. Os direitos das mulheres: feminismo e trabalho no Brasil (19171937). Rio de Janeiro: FGV, 2018.

Palavras-chave: direitos; mulheres; gênero.

Esse é um livro escrito por uma mulher sobre as longas e diversas lutas das mulheres por seus direitos no Brasil. Resultando de uma tese de doutorado, defendida no Programa de Pós-Graduação de História da Unicamp, o texto ganhou o prêmio Mundos do Trabalho de 2017, atribuído pela Associação Brasileira de Estudos do Trabalho (ABET). Prêmio merecido por inúmeras razões, dentre as quais destaco a escolha de um tema bastante frequentado, mas em recorte que o singulariza por sua abordagem, capaz de trazer contribuições e estímulos a novas pesquisas. Isso porque, ele propõe uma articulação entre dois movimentos sociais decisivos nesse processo de lutas que, mesmo tendo protagonismo evidente, costumam ser analisados, pela literatura especializada, separadamente: o movimento feminista e o movimento operário.

Tal tratamento, embora possa parecer meio óbvio e simples, está muito longe disso, oferecendo desafios diversos que vão sendo enfrentados ao longo da narrativa. Algo que está bem expresso no subtítulo do livro, também esclarecedor para o entendimento das estratégias usadas pela autora para o enfrentamento de questão tão ampla e complexa. De um lado, ela recorta o período de tempo que vai das grandes greves da Primeira República, no pós-Primeira Guerra Mundial, até a instalação do Estado Novo, em 1937, quando efetivamente se transforma a conjuntura política para lutas por quaisquer direitos, ante a instalação de um Estado autoritário. De outro, escolhe como espaço de análise a cidade de São Paulo, exemplo paradigmático de crescimento industrial no Brasil, o que lhe permite um trabalho de pesquisa mais aprofundado com fontes, como as da imprensa, além da documentação patronal, muitas vezes o único acesso para o conhecimento do que se passava com os trabalhadores no interior das fábricas e estabelecimentos comerciais.

Com esses parâmetros, Glaucia pôde construir uma narrativa em três partes e oito capítulos, que leva o leitor a acompanhar como as mulheres paulistas, durante os anos 1920/30, se organizaram no mundo do trabalho para realizar demandas que contemplassem sua condição feminina, a despeito das lideranças sindicais serem maciçamente masculinas. Como a mobilização dessas mulheres -

* Professora Titular da UFF e Professora Emérita da FGV. 
trabalhadoras têxteis, costureiras, cigarreiras, datilógrafas etc. - conseguiu chegar à política-partidária (estadual e nacional) e também a movimentos sociais, entre os quais o movimento feminista, que então se articulava e ganhava visibilidade. Como questões fulcrais para a sociedade eram também demandas centrais de direitos das mulheres trabalhadoras - a exemplo do direito à maternidade tornando-se pontos fundamentais de debates nacionais e internacionais, que envolviam o movimento feminista e as questões de regulamentação das relações do trabalho, discutidas na própria Organização Internacional do Trabalho. A OIT, nessas décadas, tem importância e influência inegáveis no encaminhamento de propostas que tinham grande ressonância, realizando convenções assinadas por vários países. Enfim, como a própria ideia de cidadania para as mulheres estava igualmente embebida nos esforços dessas lutas por direitos, reivindicados de múltiplas formas e por mulheres de condição social muito diferenciada.

É justamente para essa articulação que desejo chamar a atenção do leitor, pois é ela que nos permite acompanhar a movimentação das mulheres na reivindicação de direitos civis, políticos e sociais, em conexão, o que produz uma visão integrada de debates e ações diversos, em que o protagonismo feminino tem sempre destaque. Nesse caso, independentemente das mulheres pertencerem às elites educadas do país ou serem operárias de fábricas que participavam de greves e manifestações em busca de condições que lhes permitissem, com dignidade, exercer seu trabalho. Ou seja, o livro não trata a luta das mulheres pelo direito de voto, contrato de casamento e outros dispositivos legais que incidiam sobre suas vidas cotidianas, como uma ação desligada das batalhas que elas tinham que travar no mundo do trabalho em função de sua condição feminina. De fato, temos bons trabalhos sobre o movimento feminista que se desenvolveu no Brasil durante a Primeira República e desembocou no reconhecimento do direito de voto da mulher pelo Código Eleitoral de 1932, embora ainda se possa revisitar esse tema em diversos aspectos. Contudo, muito raramente, tais pesquisas articulam os debates nacionais e internacionais pelos direitos políticos e civis das mulheres, às lutas das mulheres trabalhadoras. Do mesmo modo, os numerosos estudos sobre movimento operário e sindical na Primeira República, mesmo ressaltando a pauta de demandas que envolvia o trabalho das mulheres - direito a não ser demitida ao engravidar; a poder continuar trabalhando e amamentar os filhos; a ter uma jornada e condições de trabalho diferenciadas pela condição feminina, entre outros - praticamente ignora qualquer correlação com o que se passava no interior do movimento feminista.

Assim, ao aproximar as lutas do movimento operário e feminista, a autora traz algumas contribuições que valem ser destacadas. Ela endossa e reforça uma crítica da historiografia mais recente a uma visão do movimento feminista como "uma história de poucas mulheres a realizar grandes feitos" (p. 85). Muito mais complexo e diferenciado internamente e muito mais conectado internacionalmente, o movimento feminista brasileiro não se esgotava na Federação Brasileira para o Progresso Feminino (FBPF), nem em Bertha Lutz, sua maior liderança, a despeito da importância de ambos. Por outro lado, Glaucia demonstra que o movimento operário, ou melhor, as mulheres trabalhadoras desse movimento, não estiveram apartadas das lutas feministas, que não eram monopólio ou exclusividade de mulheres letradas. Até porque, a condição feminina estruturava todas essas iniciativas e reivindicações, estando no cerne da "continuidade e segurança" das sociedades, já que são as mulheres as detentoras da capacidade de "reprodução da vida". Por isso, o que ia sendo postulado como 
proteção ao corpo da mulher era razão de tanta polêmica, mobilizando tantos atores e se desdobrando em questões que consideravam os "limites" do trabalho feminino, já que eram as mulheres as responsáveis pelo lar, vale dizer, pelos "cuidados" de limpeza, alimentação, criação dos filhos etc.

Também fica muito claro no livro como, quer no movimento operário quer no feminista, as discussões e cisões existiram e foram difíceis de enfrentar, sendo parte integrante desse processo de luta. Uma condição que, especialmente para a mulher trabalhadora, desencadeia uma multiplicidade de posições em disputa, que vão desde as que afastam, de forma mais ou menos radical, a mulher do mundo do trabalho, até as que, em nome da defesa da mulher, querem leis especiais de proteção ou, com o mesmo objetivo, consideram que tais leis acabam sendo uma maneira de rebaixar ou dificultar seu acesso aos postos de trabalho. Na OIT, por exemplo, desde o início do século XX, há proposições sobre a proibição do trabalho noturno de mulheres, bem como debates sobre a proteção à maternidade, que discutem tanto um sistema de financiamento dos custos desse afastamento como a duração de seu tempo. No Brasil dos anos 1910, no projeto de Código de Trabalho de Maurício de Lacerda, debatido na Câmara dos Deputados, previa-se uma licença de 100 dias, chegando-se a propor a inclusão desses custos em um sistema de seguridade, como o que seria adotado para os acidentes de trabalho em 1919. Um debate que seria retomado nos anos 1930, mas seguindo a tendência que a própria OIT passava a defender e que era a da divisão de custos entre trabalhadores, patrões e governo.

É interessante observar que, desde esse momento, estão excluídas dessa forma de proteção tanto as trabalhadoras rurais como as domésticas, adequando-se a ele apenas as trabalhadoras assalariadas urbanas. Aliás, o trabalho assalariado foi parâmetro utilizado, internacionalmente, para se montar a legislação previdenciária, da qual o campo e o serviço doméstico são consensualmente excluídos. No caso do serviço doméstico, majoritariamente feito por mulheres, muitas delas remuneradas, sequer chegava-se a considerá-lo como uma atividade produtiva para a economia do país. Não é casual, portanto, que, no Brasil, tantas décadas tenham se passado até a concessão ao trabalhador rural de direitos trabalhistas, o que só começou a ser realizado com o Estatuto do Trabalhador Rural, de 1963, com imensas resistências. No caso do serviço doméstico, a conquista de direitos pelas mulheres demorou muito mais, só ocorrendo em 2012 com a aprovação da chamada PEC das Domésticas (no feminino) que permaneceu recebendo muitas críticas.

A complexidade da defesa de direitos para as mulheres trabalhadoras é enorme e duradoura, inclusive no interior do próprio movimento operário da primeira metade do século XX, também impregnado pelo patriarcalismo da sociedade brasileira, compartilhado, nesse quesito, por outras sociedades, como a ação do movimento feminista corrobora. A percepção de que o trabalho das mulheres é prejudicial aos bons costumes e, igualmente, ao próprio trabalho dos homens, era bastante compartilhada. Um exemplo que aparece no livro é paradigmático. Já nos anos 1930, e depois da criação do Ministério do Trabalho, Indústria e Comércio, as lideranças da União dos Operários em Fiação e Tecelagem (UOFT) - categoria profissional que tinha maioria de mulheres trabalhadoras dirige-se oficialmente ao ministro para propor uma forma de melhorar as condições de trabalho no Brasil, auxiliando a solucionar a questão social. A sugestão era tão simples como impactante: o sindicato pedia que "toda mulher que trabalhasse na indústria e no comércio possa ser substituída pelo marido, irmão, tio ou pai 
desempregados da mesma profissão", sendo que gostariam que tal "resolução tivesse força de lei" (p. 62). A noção de que uma mulher não deveria trabalhar era o pano de fundo da proposta, ficando claro que sua presença no mercado depreciava o valor dos salários, numa competição "desigual” com os homens, que chegava ao ponto de lhes tirar as oportunidades, o que era indevido e deveria ser inaceitável: daí a substituição de mulheres por homens em postos de trabalho dever ter a força de lei. Porém, nada é simples e tudo, inclusive essa mesma União, está em movimento. Assim, se até 1932 a UOFT tomava posições como a descrita acima, pouco tempo depois e, segundo a ótica policial, por influência dos comunistas, defendia uma tabela de preços unificada para a manufatura de tecidos, com salário igual para trabalho igual, denunciando que a diferença de pagamento entre homens e mulheres alcançava de 20\% a 50\% a menos para elas.

Énesse mundo do trabalho, em que não só patrões como também lideranças operárias defendiam o afastamento da mulher e/ou sua baixa remuneração em relação aos homens, que as mulheres trabalhadoras tinham que defender seus interesses e sua honra (o assédio era muito comum), algumas vezes se aproximando, outras vezes se afastando e criticando o movimento feminista. Esse também em transformação, quer diante do avanço da urbanização e industrialização, quer face aos debates internacionais que chegavam ao país, até porque neles havia representação de feministas brasileiras. Além disso, havia as mudanças da conjuntura política, especialmente no pós-1930, quando se criou um ministério para as questões do trabalho e se aprovou um Código Eleitoral que deu às mulheres o direito de votar e serem votadas. É justamente nessa conjuntura que a FBPF vai caminhar em direção às demandas das trabalhadoras, envolvendo-se diretamente em temas como o do salário igual para trabalho igual, mesmo sem deixar de priorizar a defesa dos direitos políticos e civis das mulheres. Esse era o caso da luta contra as restrições impostas às mulheres casadas, que precisavam da permissão do marido para realizar uma série de ações (como assumir mandatos e receber heranças), a ele se subordinando, como cabeça do casal, em assuntos que dissessem respeito aos filhos.

Mesmo sendo muitos os feminismos, fora e dentro do Brasil, quero chamar a atenção para a movimentação da FBPF, organização muito conhecida, mas que suspeito tenha essa dimensão de atuação ainda pouco estudada. Refiro-me justamente às aproximações mais sistemáticas que passou a realizar com sindicatos, como o Sindicato de Tipógrafos e Taquígrafos, cuja presidente, em 1934, é Almerinda Faria Gama. Almerinda era também militante do movimento feminista, utilizando uma dupla tribuna para a defesa da plena igualdade jurídica da mulher, o que a levava a solicitar às autoridades a revisão da proibição do trabalho noturno das mulheres. Fazia isso, ao mesmo tempo em que acompanhava Bertha Lutz no entendimento de que não era o trabalho da mulher que causava o desemprego dos homens, não se podendo culpá-la por desejar trabalhar em busca da emancipação econômica. Como se vê, as combinatórias de demandas, sempre em nome da mulher e defendidas por mulheres, podiam ser variadas e, após a promulgação da Constituição de 1934, crescem e ganham espaço no interior da Câmara dos Deputados. Isso ocorre particularmente em 1936, quando Bertha Lutz, eleita como suplente de deputada federal, assume o cargo e vai se dedicar a dois projetos de grande envergadura: a formação de um Departamento Nacional da Mulher e a aprovação de um Estatuto da Mulher. O primeiro, com clara inspiração internacional, deveria se alocar no Ministério do Trabalho, tendo o poder de inspeção e fiscalização do trabalho feminino, o que significava que poderia impor 
as normas de proteção existentes e punir os que as desobedecessem. Também iria administrar um fundo público para o pagamento da licença maternidade de servidoras públicas e trabalhadoras de empresas privadas. Ou seja, um modelo que relia de outra maneira a experiência do pagamento de indenizações por acidentes de trabalho, em sistema de seguridade, como o já praticado no Brasil. Além disso, o novo departamento deveria ter o objetivo de desenvolver estudos que aumentassem o conhecimento sobre a condição da mulher, orientando novas políticas públicas que as beneficiassem.

Já o Estatuto da Mulher, um texto com 150 artigos, talvez possa ser entendido como uma forma de legislação que fosse capaz de contornar as prescrições do Código Civil, muito difíceis de alterar. Uma espécie de estratégia para ampliar os direitos das mulheres sem bater de frente com as limitações do Código. Nesse caso, entre muitos pontos, vale observar como ele previa que a dona de casa, que não tivesse trabalho remunerado, recebesse $10 \%$ da renda familiar em retribuição a seus serviços domésticos (p. 156), tocando no tema do trabalho doméstico, sob outro ângulo, o que evidencia como essa era uma questão difícil e polêmica, mas que era amplamente tratada como matéria política. Não cabe em uma resenha qualquer tipo de discussão maior sobre aspectos contemplados por um livro. Ela apenas os aponta e este é dos mais interessantes, deixando o leitor atento e desejoso de maior desenvolvimento. De toda forma, iniciativas de tal monta teriam que encontrar opositores de peso, como ocorreu. No caso, outra mulher liderou a oposição a Bertha Lutz e seus projetos: Carlota Pereira de Queiroz, deputada federal por São Paulo, primeira mulher eleita como integrante da Assembleia Nacional Constituinte de 1933/34. Essa observação tem o evidente propósito de deixar claro como a questão de gênero não pode ser abordada com simplismos, já que a condição de ser mulher nada tem a ver com a condição de defender direitos que, em determinadas circunstâncias históricas, estão sendo definidos como feministas. Sobretudo, quando o campo de luta é a política parlamentar e a questão em pauta toca em questões que podem ferir desde interesses patronais até a moral e os bons costumes defendidos por grupos sociais.

O livro de Glaucia Fraccaro é, em uma palavra, estimulante. Ele contribui ao colocar em foco, em determinado momento do tempo e espaço, um conjunto de problemas que integra um longo e inconcluso processo de lutas por direitos em que as mulheres têm protagonismo, quer porque estabelecem a pauta a ser reivindicada, quer porque sobre ela debatem e divergem, mas também realizam conquistas. Chega em hora propícia, pois, os direitos das mulheres, mais uma vez, estão sendo ameaçados de retrocesso pela ação de políticas públicas que minam um terreno arduamente adubado, retirando dele reconhecimento e valor, bem como verbas e tratamento privilegiado. Mas as mulheres são, como as sociedades remarcam, "cuidadoras”. Irão, assim, ter o cuidado extremo de continuar lutando pela manutenção e ampliação de seus direitos.

Recebido em 12/12/2018

Aprovado em 14/12/2018 
